\title{
Contributo do pensamento de João Paisana para uma análise da hermenêutica de Paul Ricoeur
}

\section{Luisa Nogueira}

Na sua obra, Fenomenologia e Hermenêutica - A relação entre as filosofias de Husserl e Heidegger', J. Paisana sustenta a incompatibilidade entre a fenomenologia explicitativa de Husserl e a fenomenologia hermenêtica de Heidegger. Ao longo do seu trabalho analítico e argumentativo, verificamos a importância da elucidação de conceitos que estão no cerne da distinção entre fenomenologia e hermenêutica, nomeadamente:

- Auslegung e Interpretation

- Lebenswelt e In der Welt Sein.

As precisões de J. Paisana, nomeadamente a nível dos conceitos que acabámos de assinalar, fornecem-nos uma grelha e um quadro conceptuais a partir dos quais pretendemos interpretar algumas dificuldades que detectámos em torno de conceitos importantes na hermenêutica textual de P. Ricoeur e na relação desta com a hermenêutica de Gadamer. Estamo-nos a referir principalmente aos conceitos de «mundo» e «diálogo» e às obras: Interpretation theory (1976) ${ }^{2}$, Temps et Récit 1,11,1II $(1983,84,85)^{3}$, Du texte à l'action $(1986)^{4}$.

Neste artigo, colocamos como hipótese que as dificuldades que sentimos na interpretação da hermenêutica textual de Ricoeur, longe de serem pontuais e circunscritas, derivam da sua concepção segundo a qual há compatibilidade entre a fenomenologia husserliana e a hermenêutica heideggeriana, tese que Ricoeur expressamente enuncia e justifica em «Phénoménologie et herméneutique, en venant de Husserl...»s. Agora não versaremos, no entanto, directamente sobre a tese, mas sobre as suas implicações.

1. Paisana, J. Fenomenologia e Hermenêulica - A relação entre as filosofias de Husserl e Heidegger, Editorial Presenca, Lisboa, 1992. Sempre que nos referirmos a esta obra, utilizaremos a sigia: F. H.

2 Ricoeur, Interpretation theory: Discourse and the Surplus of Meaning, The Texas Christian University Press, 1976. Sempre que nos referirmos a esta obra, utilizaremos a sigla: T.I. Utilizaremos a tradução portuguesa de Artur Morão, Teoria da Interpretação - o Discurso e o Excesso de Significação, Lisboa, Edições 70, 1987.

3 Ricoeur, Temps et récit I, Éditions du Seuil, Paris, 1983; Temps el récit II, Éditions du Seuil, Paris 1984; Temps et récit III, Éditions du Seuil, Paris 1985. Sempre que nos referirmos a estas obras, utilizaremos as siglas T.R.I, T.R.II, T.R.III.

4 Ricoeur, Du texte à l'action, Éditions du Seuil, Paris, 1986.

$s$ Artigo publicado pela primeira vez em 1975, in E. W. Orth (ed.), Phänomenologische Forschungen, 1, Fribourg-en-Brisgau, Verlag Karl Aber, pp. 31-71; publicado em T.A. pp. 39-73. 
A ser consistente a hipótese de que partimos e guiados pelo pensamento de J. Paisana, são de esperar também algumas dificuldades na aproximação que Ricoeur pretende realizar à hermenêutica de Gadamer, já que para este, tal como para J. Paisana (e contra Ricoeur), os projectos husserliano e heideggeriano se devem considerar incompativeis ${ }^{6}$.

O que nos propomos fazer é, de algum modo, um exercício hermenêtico: o de ler Ricoeur a partir de J. Paisana. A conseguirmos o nosso intento, mostraríamos a riqueza e fecundidade das precisões conceptuais de J. Paisana na obra citada e a importância da sua proposta hermenêutica, filiada em Heidegger, em História da Filosofia e tradição filosófica? ${ }^{7}$.

\section{§ 1 Importância da distinção entre «Auslegung» $\mathbf{e}$ «Interpretation»}

Afirma Ricoeur em Du texte à l'action, referindo-se ao que considera ser a pressuposição hermenêutica da fenomenologia: «Por pressuposição hermenêutica, entendo essencialmente a necessidade para a fenomenologia de conceber o seu método como uma Auslegung, uma exegese, uma explicitação, uma interpretação» ${ }^{8}$. Ora, segundo J. Paisana, nenhum destes termos é equivalente e a sua indistinção liga-se a uma indistinção conceptual de pesadas consequências. Seguindo de muito perto a análise de J. Paisana, consideraremos que, se Auslegung pode ser traduzido por explicitação em Husserl, deve ser traduzido por interpretação (nível ôntico) em Heidegger ${ }^{9}$. O termo «exegese», por seu lado, deveria diferenciar-se, colocando-se

6 Na última Parte da sua obra (capítulo $2, \S 1$ ), J. Paisana dá conta do carácter «controverso» da questão da conciliabilidade ou incompatibilidade da fenomenologia explicitativa husserliana e da fenomenologia hermenêtica heideggeriana, apresentando a seguinte síntese: «Esta questão é tanto mais controversa quanto os comentadores mais qualificados se mostram bastante longe de um acordo sobre tal ponto; assim, por exemplo, Otto Pögeler, Jean Beaufret e Hans Gadamer, a conciliação revela-se impossível. O pensamento de Heidegger só seria compreensível a partir de uma ruptura inconciliável com a fenomenologia husserliana. Por contra, para pensadores como Paul Ricoeur, E. Levinas e sobretudo Merleau-Ponty, a conciliação seria não só possível, como as próprias fenomenologias de Husserl e Heidegger seriam no limite complementares». Paisana, ob. cit. p. 259.

7 Paisana, História da Filosofia e Tradição filosófica, ed. Colibri, Lisboa, 1993. Sempre que nos referirmos a esta obra, utilizaremos a sigla H.F.T.F.

8 «Par présupposition herméneutique, j'entends essentiellement la necessité par la phénoménologie de concevoir sa méthode comme une Auslegung, une exégèse, une explicitation, une interprétation». Ricoeur, T. A., p. 63.

9 «Na verdade, o termo 'Auslegung' é utilizado tanto por Husserl como por Heidegger, embora naturalmente com sentidos bem distintos.

O termo poderia ser traduzido quer por 'explicitação' em Husserl, quer por 'interpretação' em Heidegger. Não podemos no entanto utilizar a mesma tradução para ambos os autores, porque para Husserl o termo situa-se sempre a nível temático, ao passo que para Heidegger o termo é predominantemente não temático. Para Husserl, 'Auslegung' implica sempre a tematização do que é explicitado (...).

Para Heidegger, ao inverso, não pensamos que o termo 'Auslegung' possa ser traduzido por 'explicitação' porque, precisamente ao interpretar o Dasein não tematiza necessariamente o sentido interpretado (...).

Quando Heidegger fala de uma interpretação temática, expressa - isto é, explícita -, utiliza não o termo 'Auslegung', mas 'Interpretation' (que traduzimos por 'exegese') (...)» Paisana, F. H. nota de rodapé pp. 285-286. 
a nível ontológico, e como tradução do termo utilizado por Heidegger, Interpretation. Nesta sequência, se a distinção em Heidegger entre interpretação (Auslegung) e exegese (Interpretation) significa a delimitação clara dos planos pré-ontológico e ôntico relativamente ao ontológico, o uso indiscriminado dos termos significará também que esses níveis não se encontram claramente dilucidados. É a primeira consequência que retiramos da tradução indiferenciada dos termos que assinalámos. Nesta medida o projecto de uma hermenêutica guiada pela questão ontológica poderá apresentar dificuldades. Seguindo a mesma ordem de ideias, se em Heidegger o questionar é condição da exegese e se só a actividade questionante permite passar de um ponto de vista ôntico-existencial a um ponto de vista ontológico-existenciário, então a actividade hermenêutica teria que se desenvolver necessariamente a partir do questionar ${ }^{10}$. A ausência da distinção entre a actividade interpretativa associada à estrutura do Dasein, não tematizada portanto, e a actividade de exegese enquanto momento ontológico e questionamento expresso, retiraria aquele carácter de necessidade ao acto de questionar. É o que acontece com Ricoeur, ao recusar o diálogo como modelo da actividade hermenêutica (conotado com a hermenêutica romântica de Schleiermacher e limitado à situação de oralidade) e ao fazer do «paradigma da leitura» o modelo da actividade hermenêutica. Deste modo, teremos de perguntar como seria possível a aproximação a Gadamer, para quem, pelo contrário, a «lógica da pergunta-resposta» constitui a essência do fenómeno hermenêutico e o diálogo é considerado o modelo de toda a interpretação.

\section{$\S 2$ O papel do «mundo do texto» na hermenêutica de Ricoeur}

Situemo-nos, entretanto, no âmbito mais restrito da proposta da hermenêutica textual de Ricoeur. Lembremo-nos que a hermenêutica ricoeuriana se situa na tradição hermenêutica da exegese textual incluindo os contributos fundamentais de Scheiermacher e de Dilthey. A hermenêutica textual de Ricoeur, articulada em torno da sua teoria do texto, pretende reunir os contributos desta tradição, da filosofia de Heidegger e da hermenêutica de Gadamer (dando sequência, nomeadamente, às preocupações epistemológicas a que estes últimos não teriam dado resposta satisfatória), no âmbito da tradição da filosofia reflexiva.

A teoria do texto organiza-se, para Ricoeur, tendo como conceito central o da autonomia semântica do texto. É a partir daqui que deriva conceitos hermenêuticos fundamentais como: autor, mundo, leitor. A autonomia do texto, ligada à escrita, $a$ tripla autonomia, significa que este se libertou do seu autor, das condições que lhe deram origem e do auditório primitivo abrindo-se a uma pluralidade de leitores. Daqui Ricoeur tira como consequência:

1. O autor não tem papel no processo interpretativo a nível do critério de validade das interpretações.

2. O objecto da interpretação não é a intenção do autor mas o mundo do texto.

10 «O questionar surge assim como o primeiro momento da exegese ontológica. Porque a ontologia não tem um objecto material próprio, mas o seu âmbito é determinado pelo próprio questionar, é que podemos aproximar este momento da exegese fenomenológica do que Heidegger chama redução do ente ao ser. (...) É assim, pelo questionar, que as possibilidades de ser no mundo projectadas pelo Dasein, e vividas apenas de modo não temático, podem ser abertas como possibilidades expressas». Paisana, F. H. p. 289. 
3. O leitor é quem actualiza a significação do texto. O último momento do processo interpretativo é a apropriação.

Sabendo que o «mundo do texto é o centro de gravidade da questão hermenêutica»" ${ }^{11}$, interessa-nos trabalhar duas questões:

1. ${ }^{\text {a }}$ Qual a importância de determinar o mundo do texto como objecto da interpretação?

2. ${ }^{\text {a }}$ Qual a semântica de "mundo» nos diversos contextos em que aparece (mundo do texto, mundo do leitor, mundo real, mundo efectivo...) e de que modo ele se conecta com os conceitos de Lebenswelt e In-der-Welt-Sein?

Se bem que logicamente a segunda questão devesse aparecer em primeiro lugar, parece-nos mais claro determinar primeiro a função que o conceito de mundo começa por exercer e só depois procurar o seu esclarecimento.

A hermenêutica textual de Ricoeur pretende afastar qualquer risco de queda no psicologismo. Se compreender (Verstehen) um texto não é nem recuperar a intenção do autor nem um processo de transferência na vida de outrem (contra Schleiermacher e Dilthey), não é também um processo guiado pela subjectividade do leitor. Antes de analisarmos o significado mais preciso dos termos que estamos a usar, podemos afirmar desde já que, seguindo Ricoeur, compreender um texto é aceder ao seu mundo. Colocando o "mundo» como elemento exterior ao texto, embora projectado por ele, 'assim como fora da esfera subjectiva do autor ou do leitor, podemos considerar que a interpretação não corre o risco de queda em qualquer perspectiva psicologista. Esta é a primeira função que se atribui ao «mundo do texto»: despsicologizar a interpretação. Mas assim como, deste modo, Ricoeur se afasta da hermenêutica romântica, também se irá afastar da análise semiológica ou melhor, do estruturalismo como «modo global de pensamento» ${ }^{12}$. Concebendo o «mundo» como fora da esfera das relações imanentes que o texto enquanto obra e produção escrita permite isolar e determinar numa rede lógica, a sua determinação como objecto da hermenêutica obriga a considerar a insuficiência de uma análise que esqueça as relações entre texto e mundo (seja qual for a forma de encarar e definir mais precisamente estes conceitos). Segunda função: o mundo do texto, como objecto da actividade hermenêutica, exige a ultrapassagem da perspectiva de análise semiológica e estrutural. A «abertura» da linguagem de que Ricoeur falava em Le conflit des interprétations (1969) no âmbito de uma hermenêutica dos símbolos, é agora, na hermenêutica textual, representada pelo conceito de «mundo» ${ }^{13}$.

As duas funções do conceito de mundo que acabámos de considerar parecem-nos claramente estabelecidas nos textos de Ricoeur. Mas o aspecto que nos levanta algumas dificuldades diz respeito ao facto de ser através do conceito de «mundo» que Ricoeur pretende colocar a hermenêutica na esteira de Heidegger e de Gadamer. Não se trata apenas de despsicologizar a interpretação ou evidenciar as limitações do modelo estruturalista, trata-se de colocar o processo interpretativo em solo ontológico. Mas, para isso, não teria sido necessária a elaboração de um

11 T.A., p.102

12 Em T. I., esclarecendo «os postulados do modelo estrutural» conclui: «O último postulado basta, só por si, para caracterizar o estruturalismo como um modo global de pensamento, para lá de todos os aspectos técnicos da sua metodologia. A linguagem já não aparece como uma mediação entre as mentes e as coisas. Constitui um mundo próprio, dentro do qual cada elemento se refere apenas a outros elementos do mesmo sistema, graças à acção recíproca das oposições e diferenças constitutivas do sistema». Ricoeur, T. I, p. 18.

: 3 Cf. Ricoeur, Le conflit des interprétations, "La structure, le mot, l'évènement», Éditions du Seuil, Paris, 1969, pp. 80-97. 
conceito ontológico de mundo de forma clara e suficientemente tematizada? Passemos então à segunda questão: $\mathrm{O}$ que devemos entender por «mundo»? Podemos pensá-lo em quatro observações interconectadas:

1. O mundo corresponde à dimensão significativa do texto enquanto obra do discurso e da linguagem. A intencionalidade do texto deriva da intencionalidade da linguagem num sentido fenomenológico. O mundo deve ser entendido como o «horizonte» de significabilidade a partir do qual se compreendem os elementos textuais e o texto como unidade. O mundo é, assim, uma totalidade não dada, a partir da qual se constitui a significação. Nesta medida é um conceito de raiz fenomenológica.

2. $\mathrm{O}$ mundo equivale à «coisa» do texto de Gadamer: «.... tarefa hermenêutica é discernir a 'coisa' do texto (Gadamer) e não a psicologia do seu autor». Identificando "coisa» do texto com «mundo que o texto projecta» ${ }^{14}$, Ricoeur evidencia que aquilo sobre que versa a compreensão escapa à subjectividade (tanto do autor como do leitor) e que a leitura não é um encontro entre subjectividades.

3. O mundo é abertura de possibilidades existenciais: «... a espiritualidade do discurso manifesta-se pela escrita, libertando-nos da visibilidade e da limitação das situações, abrindo-nos um mundo, a saber, novas dimensões do nosso ser-no-mundo ${ }^{15}$. Neste sentido, o mundo aponta a dimensão existencial e a direcção ontológica de toda a interpretação. Ricoeur evidencia, deste modo, a influência de Heidegger.

4. O mundo é a «referência» do texto/obra: « Do mesmo modo que o texto liberta a sua significação da tutela da intenção mental, ele liberta a sua referência dos limites da referência ostensiva. Para nós, o mundo é o conjunto das referências abertas pelos textos» ${ }^{16}$. Para poder sustentar e esclarecer a sua tese de que o mundo é a referência da obra, Ricoeur elaborou uma teoria da referência, distinguindo referência ostensiva ou de primeiro grau e referência desdobrada ou de segundo grau. Elaborada principalmente em La Métaphore Vive (1975), no âmbito dos estudos sobre a metáfora e o discurso poético, a teoria da referência do discurso visa incluir, sob a mesma designação de referência, os usos não descritivos da linguagem. A teoria da referência, no entanto, acabará por ser considerada, por Ricoeur, como insuficiente. Tanto a elaboração de uma teoria da leitura em Témps et récit III, enquadrada pela teoria da mimesis, como a deslocação do problema da significabilidade da obra para o âmbito das questões da comunicação, da consciência histórica e da intersubjectividade, pretendem ultrapassar as dificuldades em torno da aplicação da dicotomia entre sentido (Sinn) e referência (Bedeutung) à unidade da obra, sob influência da análise fregeana da proposição. O conceito de mundo

14 "...la tâche herméneutique est de discerner la 'chose' du texte (Gadamer) et non la psycologie de l'auteur. La chose du texte est à sa structure ce que, dans la proposition, la référence est au sens (Frege). De même que, dans la proposition, nous ne nous contentons pas du sens qui est son objet idéal, mais nous nous interrogeons en outre sur sa référence, c'est à dire sa prétention et sa valeur de vérité, de même, dans le texte, nos ne pouvons nous arrêter à la structure immanente, au système interne de dépendances issues de l'entrecroisement des 'codes' que le texte met en oeuvre; nous voulons en outre expliciter le monde que le texte projette». Ricoeur, T. A., p. 52.

is "...la spiritualité du discours se manifeste par l'écriture, en nous libérant de la visibilité et de la limitation des situations, en nous ouvrant un monde, à savoir de nouvelles dimensions de notre être-au-monde». Ricoeur, T. A., p. 189.

16 «De la même manière que le texte que le texte libère sa signification de la tutelle de l'intention mentale, il libère sa référence des limites de la référence ostensive. Pour nous, le monde est l'ensemble des références ouvertes par les textes». Ibidem, p. 188. 
do texto aparecerá, de modo dinâmico, em relação com o de mundo do leitor e a significabilidade como resultado de um processo de «entrecruzamento» destes dois mundos: do mundo do texto, definido como fíctício, e do mundo do leitor, definido como real e efectivo. Ricoeur realiza, nesta obra, uma aproximação à estética da recepção de Jauss, à estética fenomenológica (Ingarden e Iser) e à tradição hermenêutica num sentido mais restrito, recuperando a temática da "aplicação» ${ }^{17}$. Ficamos, assim, longe da colocação do problema da referência em termos próximos da tradição lógica, tal como acontecia, principalmente, em La Métaphore Vive. Neste novo enquadramento, que coloca o acto interpretativo sob o paradigma da leitura, o conceito de mundo aparece-nos mais próximo de uma teoria hermenêutica da comunicação.

No entanto, seja qual for o sentido ou a explicitação que se faça do conceito de mundo, ele é sempre determinado como o objecto da hermenêutica, como aquilo que é visado em toda a interpretação, oscilando entre uma conotação fenomenológica husserliana ou ontológica, sob influência de Heidegger e de Gadamer. O mundo do texto em Ricoeur aponta, em qualquer circunstância, para o sentido de toda a interpretação e sua direcção ontológica, assegurando a vertente ontológica da hermenêutica. Diz Ricoeur que ele deve ser interpretado tanto no sentido do Lebenswelt como no de In-der-Welt-Sein. Esta identificação é clara, por exemplo, na seguinte citação a propósito do esclarecimento do conceito de referência de segundo grau, «em que o mundo é manifestado não mais como conjunto de objectos manipuláveis, mas como horizonte da nossa vida e do nosso projecto, logo como Lebenswelt, como ser-no-mundo» ${ }^{18}$.

Toda a actividade hermenêutica consiste em desdobrar o mundo do texto, em explicitar esse horizonte de sentido que a orienta e direcciona. O mundo é, ao mesmo tempo, a referência do texto. Esta referência radica, por seu lado, no facto de todo o discurso, enquanto linguagem, ter como ponto de partida a experiência de ser-no-mundo (a condição ontológica da linguagem). Assim, dizer que todo o texto tem um mundo, significa ao mesmo tempo:

1. que a experiência de ser-no-mundo é a raiz de toda a actividade significativa/ interpretativa, pelo que tanto o sujeito-autor quanto o sujeito-leitor se subordinam a esta condição prévia. A experiência de ser-no-mundo precede qualquer actividade hermenêutica.

2. que o mundo do texto se desdobra à frente do texto e não atrás, como uma intenção escondida.

Deste modo, o mundo do texto cumpre em simultâneo o papel daquilo que precede toda a actividade hermenêutica e daquilo que orienta a actividade hermenêutica, num caso como noutro, entendida como actividade de exegese textual. O mundo é, em simultâneo, condição e tema da interpretação. Detectamos, assim, alguma ambiguidade no conceito: enquanto considerado «o que precede» situa-se a nível ôntico-existencial; enquanto o que surge "à frente», situa-se a nível ontológico. Vemos, deste modo, que o conceito de mundo deve considerar-se tanto a um nível de pré-compreensão ontológica, daí o ser considerado como horizonte

17 Cf. Temps et récit III, capt. 4 «Monde du texte et monde du lecteur», pp. 228-263.

18 «Mais c'est précisément dans la mesure où que le discours de la fiction 'suspens' cette fonction référentielle de premier degré qu'il libère une référence de second degré, où le monde est manifesté comme non plus comme ensemble d'objets manipulables, mais comme horizon de notre vie et de notre projet, bref comme Lebenswelt, comme être-au-monde». Ibidem p. 52. 
prévio de significabilidade, como a um nível de compreensão ontológica, como abertura de novas possibilidades. Todo o texto revela quer um mundo de onde partiu, quer uma direcção, o mundo revelado como «modo possível de ser», "projecção de possibilidades», novas dimensões do nosso «ser-no-mundo». No primeiro sentido, o mundo está associado à situação hermenêutica do intérprete; no segundo sentido, ao resultado da tarefa hermenêutica explicitamente considerada ${ }^{19}$. Enquanto condição da interpretação, o mundo pertence à estrutura do Dasein enquanto autointerpretado e tendo já respondido à questão que interroga pelo sentido do seu ser (de modo existencial e não temático). Enquanto tema da interpretação, o mundo é a abertura de possibilidades que só a tarefa hermenêutica permite pôr a descoberto. $\mathrm{O}$ que parece não acontecer em Ricoeur, é a articulação de modo claramente explícito destes dois momentos. Se a distinção é feita apenas de modo implícito, não pode por isso ser expressamente nomeada e, portanto, a questão da transição do nível ôntico para o ontológico também não pode colocar-se de modo expresso. Ora, esta distinção e esta questão são decisivas, segundo J. Paisana, para uma hermenêutica que se filie em Heidegger e ligam-se à distinção entre o acto de interpretar enquanto pertencendo à estrutura do Dasein (Auslegung) e a actividade de exegese (Interpretation) enquanto actividade tematizada, enquanto tarefa, como vimos, necessariamente questionante.

Alguma falta de clareza que acabamos de assinalar em Ricoeur relativamente ao conceito de «mundo», embora a sua função na economia do pensamento ricoeuriano seja clara, poderá então estar ligada à ausência de delimitação expressa e sistematizada entre os níveis pré-ontológico e ontológico. E esta, por sua vez, não está dissociada da ausência de um conceito ontológico de exegese.

Num outro tipo de exemplo, corroborando a nossa posição, verificamos que, se Ricoeur considera, lendo Aristóteles, a interpretação como «interpretação pela linguagem antes de ser interpretação sobre a linguagem $\rangle^{20}$, não continua a análise a ponto de distinguir, de modo explícito e preciso, o nível da interpretação implícita e o nível da interpretação tematizada como Heidegger lho permitiria. De modo semelhante, quando comentando Ser e Tempo, afirma que «antes da exegese dos textos, vem a exegese das coisas ${ }^{21}$, vemos que a palavra "exegese" na expressão «exegese de textos» se situa ao nível da interpretação tematizada expressa e a mesma palavra na expressão «exegese das coisas» se situa a nível pré-ontológico ou ôntico-existencial. O uso de aspas na seguinte transcrição, para usar outro exemplo, é o recurso linguístico que utiliza para distinguir os níveis da interpretação, aqui no âmbito dos símbolos: «Se uma epigénese da pulsão e do fantasma é possível, é porque a palavra é o instrumento desta hermeneia, desta 'interpretação' que o

19 Segundo a proposta hermenêutica de J. Paisana, devemos distinguir claramente a situação hermenêutica da tarefa hermenêutica: "O pensamento hermenêutico exige então a consideração de dois níveis: a caracterização da situação histórica, em que o leitor sempre se encontra; a caracterização da tarefa hermenêtica, que o leitor pode, ou não, levar a cabo». E esclarecendo estes dois momentos notamos que o primeiro momento da tarefa hermenêutica é o do questionamento: «a tarefa hermenêutica (...) caracteriza-se: 1) pela redução ou questionamento do texto (...)». J. Paisana, H.F.T.F., p. 23.

20 «...je retiens d'Aristote l'idée que l'interprétation est interprétation par le langage avant d'être interprétation sur le langage». Ricoeur, T. A., p.157.

21 «Ce n'est donc qu'en troisième position dans la triade situation-compréhension-interprétation qui vient le moment ontologique qui intéresse l'exégète. Mais avant l'exégèse des textes, vient l'exégèse des choses». Ibidem, p. 92. 
próprio símbolo exerce relativamente ao fantasma, antes mesmo de ser 'interpretado' pelo exegeta» ${ }^{22}$.

\section{$\S 30$ «mundo da vida»}

Não devemos considerar alheia a esta dificuldade a equivalência que Ricoeur faz entre o mundo da vida (Lebenswelt), segundo Husserl, e ser-no-mundo, In-derWelt-Sein, segundo Heidegger. Seguindo a análise de J. Paisana, vemos que o mundo da vida é ante-predicativo mas não pré-objectivo, referindo-se sempre a um mundo de objectos já constituídos enquanto tais. Diferentemente, o ser-no-mundo situa-se não só a um nível ante-predicativo e pré-categorial, mas também pré-objectivo. A estrutura da significação será a estrutura hermenêutica «enquanto que», relativamente à qual a estrutura apofântica é derivada ${ }^{23}$.

O conceito husserliano de Lebenswelt permite-nos, segundo Ricoeur, conciliar a fenomenologia de Husserl com a hermenêutica de Heidegger. Ricoeur considera, não só que o carácter presuntivo da percepção pode ser alargado à experiência histórica como fez Merleau-Ponty, mas principalmente que é o «retorno da natureza objectivada e matematizada à Lebenswelt (...)» que acaba por desempenhar «um papel paradigmático para a hermenêutica» ${ }^{24}$. Sendo assim, a hermenêutica continuaria este gesto de Husserl, mas obrigando ao abandóno do idealismo. Neste sentido, a hermenêutica seria então a própria realização do projecto fenomenológico.

Para Ricoeur, o mundo da vida é o excesso de sentido inesgotável no qual e a partir do qual se constitui a ordem do discurso e do texto enquanto organizadores da experiência. Seria a admissão deste «excesso» que obrigaria a abandonar a intuição e a redução nos termos husserlianos e o projecto de constituição do ego. No entanto, isto não significa em Ricoeur o abandono do conceito de consciência e da sua estrutura intencional ou da concepção da constituição do sentido de modo explicitativo e reflexivo, apenas o abandono da concepção da subjectividade transcendental e da possibilidade de um fundamento último. Ricoeur não abandona nem o conceito de consciência nem o de subjectividade, embora os corrija, quer pela pertença do sujeito ao mundo e pela sua dimensão não reflectida, quer pela «objectividade». O ser-no-mundo, como estrutura do Dasein e condição do sujeito, significam tão só o nível não reflectido, a partir do qual se geram obras e interpretações. É esse nível implícito e nunca absolutamente tematizado que a interpretação expressa, a exegese, ilumina. A exegese será, em certo sentido, um retorno a camadas de sentido que só com e pela interpretação se clarificam e explicitam, revelando ao intérprete/sujeito «novos aspectos de ser-no-mundo». Para Ricoeur, a situação de ser-no-mundo, em que as coisas significam antes de se constituirem tematicamente para uma consciência teorética, pode representar, para a constituição do sentido, o mesmo papel que o mundo da vida enquanto «reserva»

Ricoeur, De l'interprétation.Essai sur Freud, Éditions du Seuil, Paris, 1965, p. 522. «A significação, em sentido originário, não é ainda um ponto de vista parcial sobre o objecto, mas situando-se ao nível do comportamento pré-objectivo, tem as suas raízes na articulação da estrutura 'enquanto que' hermenêutica». Paisana, H.F., p.132

«Le retour à la Lebenswelt peut d'autant mieux jouer ce rôle paradigmatique pour l'herméneutique que la Lebenswelt n'est pas confundue avec je ne sais quelle immédiateté ineffable et n'est pas identifiée à l'enveloppe vitale et émotionnelle de l'expérience humaine, mais désigne cette réserve de sens, ce surplus de sens de l'expérience vive, qui rend possible l'attitude objectivante et explicative». Ricoeur, T.A., p. 62. 
e «excesso» de sentido. Embora Ricoeur pareça situar frequentemente a significação a nível pré-objectivo, não a analisa nem equaciona como suficientemente diferenciadora a ponto de impedir a equivalência entre os conceitos de «mundo» em Husserl e em Heidegger. Analisando a «crítica hermenêutica do idealismo husserliano», concorda com a posição heideggeriana segundo a qual a «noção de sentido obedece à (...) dupla condição do enquanto que (als) e da antecipação (Vor)» para poder concluir com a proposição, que manterá na sua hermenêutica, de que «o campo da interpretação é tão vasto como o da compreensão, a qual cobre qualquer projecção de sentido numa situação» ${ }^{25}$. Os conceitos de «interpretação» e «explicitação», que Ricoeur utiliza para a tradução de Auslegung, aparecem sem relação expressa com a distinção entre os planos ôntico e ontológico. O que Ricoeur não deixa suficientemente claro, então, é a relação entre a estrutura interpretativa enquanto que (Als Struktur) - a estrutura hermenêutica (existenciária) - e a estrutura enquanto que do enunciado predicativo, a estrutura apofântica ${ }^{26}$. Não trabalhando esta diferença não haverá razões para distinguir o «mundo» no sentido heideggeriano associado à situação hermenêutica do Dasein (ante-predicativo e pré-objectivo), e o «mundo» no sentido husserliano de horizonte nunca dado (antepredicativo mas não pré-objectivo $)^{27}$. Nesta sequência, poderemos dizer também que as «ciências positivas», que Ricoeur sempre considerou do domínio do saber objectivo - nível apofântico -, podem integrar-se no campo da interpretação sem que a questão da transição do nível ôntico para o ontológico se coloque.

Em Soi-Même Comme un Autre (1990), no último estudo, Ricoeur afirma que o conceito de mundo ainda não tinha sido suficientemente tematizado e, em nota de rodapé, diz tão só: «O conceito de horizonte vindo de Husserl, ou o de mundo no sentido de Heidegger, não foram estranhos à minha obra passada. Na Metáfora viva advogo a ideia de verdade metafórica que tem por horizonte o mundo no qual temos a vida, o movimento e o ser. Num espírito vizinho, Temps et récit confronta o mundo do texto e o mundo do leitor ${ }^{28}$. Depois da complexidade do conceito de mundo e sabendo que este é o conceito fundamental a partir do qual Ricoeur pretende assegurar a vertente ontológica da hermenêutica textual, não poderemos ver aqui razões acrescidas para as dificuldades que temos vindo a levantar? E se a actividade hermenêutica permitirá a transição do ego ao soi, através do conceito de mundo, não poderemos sustentar que o si reflexivo que se reconhece no final do acto interpretativo não é ainda o Soi, e que só uma ontologia da ipseidade tal como

25 Cf. Ricoeur, T. A., pp. 40-55.

26 «Assim, pela predicação todos os momentos da estrutura interpretativa sofrem profundas alterações que vão tornar possível o aparecimento da conduta teorética, a partir da preocupação quotidiana reflectindo tais alterações, Heidegger distingue o 'enquanto que' hermenêutico-existenciário da interpretação compreensora, do 'enquanto que' apofântico da predicação». Paisana, H. F., p. 157.

27 «O mundo da vida, embora dado, segundo Husserl, através de actos ante-predicativos, constitui-se sempre como um horizonte de objectos, enquanto que para Heidegger a concepção de mundo encontra-se em primeiro lugar com o significarn. Ibidem, p. 309. «Le concept d'horizon, venu de Husserl, ou celui de monde au sens de Heidegger, n'on. pas été étrangers à mon oeuvre passée. Dans La Métaphore vive, je plaide pour l'idée de vérité métaphorique, qui a pour horizon le monde dans lequel nous avons la vie, le mouvement et l'être. Dans un esprit voisin, Temps et Récit confronte le monde du texte au monde du lecteur». Ricoeur, Soi-même comme un autre, Éditions du Seuil, Paris, 1990, p. 360 . 
se configura em Soi-même, permitirá dar uma consistência ao Soi, que a hermenêutica textual não consegue?

\section{$\S 4$ Compreender e explicar}

Compreender e explicar são a via de acesso à significação textual. A «rica ambiguidade» que Ricoeur considera haver no termo compreender acaba por significar os diferentes níveis em que deve ser considerado. Portanto, diremos que não há ambiguidade se distinguirmos claramente os níveis, nomeadamente, o préontológico e ontológico, o nível existencial não tematizado e o nível da tematização expressa. É com essa distinção implícita que Ricoeur aborda os diversos significados do termo, e é a distinção nos conceitos correlativos de interpretação e exegese que a perspectiva hermenêutica de J. Paisana estabelece de modo incisivo e determinante, que nos ajudará na análise do texto de Ricoeur ${ }^{29}$.

Primeiro: compreender é o modo próprio do Dasein. Compreender é sempre orientação numa situação. Estamos no nível da compreensão não tematizada, nos planos pré-ontológico e existencial.

Segundo: se o perspectivarmos na relação com o momento da explicação, o termo deve ser entendido como momento do "compreender prévio». Numa perspectiva epistemológica é considerado um momento não metódico nem tematizado. $\mathrm{O}$ conceito de «comprender prévio» deverá estar associado ao conceito de pré-compreensão como consequência da situação hermenêutica do intérprete/ IDasein (nível ôntico-existencial). Associado ao conceito de pertença, evidencia o nível pré-ontológico de toda a actividade interpretativa e hermenêutica.

Terceiro: compreender é perspectivado como operação de ligação, união, síntese, de ligação de partes num todo. Fiel ao seu sentido etimológico (prender com) é fundamentalmente como operação cognitiva que é também considerado.

Quarto: deve ainda observar-se que, se compreender é um existencial, pode desenvolver-se tematicamente como compreensão ontológica. Esta é uma consequência do $1 .^{\circ}$ sentido. Este último nível da compreensão - após a fase explicativa - o que Ricoeur considera ser a compreensão da semântica profunda, o do acesso/descoberta do mundo do texto, parece dever situar-se a este nível ontológico de compreensão. Através da mediação dos procedimentos explicativos (científicos), a compreensão ocorre pela «fusão de horizontes» do texto e do intérprete/leitor, conceito que Ricoeur retira da hermenêutica de Gadamer. No entanto, este nível não nos parece plenamente elucidado.

Finalmente, compreender é apropriar-se da significação do texto. Corresponde à última etapa do processo interpretativo: o momento em que a reflexão se torna «concreta», o momento da «compreensão de si», da «apropriação» existencial.

29 Na verdade, segundo o que dissemos, a mais simples leitura será sempre interpretativa, mas não implica necessariamente uma exegese expressa. Por isso é necessário distinguir com firmeza entre exegese e interpretação. Na interpretação a questão não é explicita mas velada; por contra, a exegese só é possivel a partir da questão expressamente formulada. (...) Será necessário introduzir, como fizemos, uma distinção capital, geralmente ignorada mesmo pelos autores que se reclamam expressamente do pensamento hermenêutico. Referimo-nos à distinção entre interpretação e exegese». Paisana, H.F.T.F., pp. 21-22. 
Antes de problematizarmos alguns destes aspectos, passemos à sistematização do conceito de explicação:

Primeiro, explicar é um conceito epistemológico associado às ciências. Se bem que Ricoeur se distancie de Dilthey, rejeitando o dualismo explicar-compreender e o significado psicológico do termo compreender, a tarefa da explicação continua a estar associada aos procedimentos analíticos das ciências, embora precisada de modo distinto e num quadro epistemológico diferente em que a linguagem adquiriu estatuto de «objecto» de ciência. $\mathrm{O}$ «rigor» analítico que Ricoeur vê realizado no trabalho explicativo sobre o texto, mais do que considerado, deve ser integrado no percurso da sua hermenêutica filosófica e reflexiva. Se bem que a condição hermenêutica de todo o saber limite os conceitos de ciência e de objectividade, o universo das ciências não deixa de se constituir como um dado que cabe à Filosofia integrar.

Em segundo lugar, de um ponto de vista meramente cognitivo, explicar pode ser considerado uma operação de análise e segmentação.

Terceiro: a explicação, tal como foi anteriormente considerada, deve, no entanto, subordinar-se ao compreender prévio. Referimo-nos ao primeiro sentido que apontámos relativamente ao termo compreender. Nesta perspectiva, o momento explicativo na hermenêutica deve ser entendido como explicitação analítica da compreensão ou desenvolvimento tematizado das possibilidades inscritas no texto.

Quarto: o momento explicativo constitui-se como uma etapa metodológica necessária para uma compreensão de nível superior. Caracteriza-se por colocar em suspenso as referências do texto - o mundo - e abstrai do sujeito (quer na forma do autor, quer na forma do leitor) e da historicidade. Esta etapa adquire uma feição autónoma, se desenquadrada da unidade do processo hermenêutico, correspondendo aos procedimentos científicos de análise textual. Na unidade do processo hermenêutico, é o momento abstracto da análise do sentido do texto enquanto estrutura imanente.

Por último, podemos dizer que a explicação se constitui como momento da exegese, não só legítimo - devido à especificidade do universo da escrita - como necessário. $\mathrm{Na}$ hermenêutica ricoeuriana, constitui a mediação para a última etapa da interpretação, a da apropriação e compreensão de si, em que a reflexão se torna «reflexão concreta» ${ }^{30}$.

Posto isto, o que precisamos de compreender é: como é que a análise objectiva dos textos pode garantir o acesso ao nível ontológico? De que modo é que a etapa explicativa, que se situa a um nível ôntico, segundo Heidegger, poderá assegurar a transição para o nível ontológico? Como se justifica a integração necessária da etapa explicativa, o momento da objectividade, no processo interpretativo?

Comecemos pela última questão. Se nos ativermos ao que Ricoeur diz, teremos de considerar várias ordens de razões. A mais imediata encontra-se na sua teoria do texto e da escrita: o carácter complexo do texto enquanto produção escrita e a sua inserção no universo regulado pelos códigos específicos da literatura exigem o rigor de análise que as ciências do texto permitem. Uma segunda razão pode ser encontrada no facto de a hermenêutica se encontrar filiada em Dilthey, o que justifica as preocupações epistemológicas de Ricoeur: a teoria do texto e a sua extensão paradigmática ao campo da acção permitem a superação da dicotomia diltheyana e

30 «L'objectivité structurale peut alors apparaître comme un moment abstrait - et valablement abstrait - de l'appropriation et de la reconnaissance par laquelle la réflexion abstraite devient refléxion concrète». Ricoeur, Le conflit des interprétations, p. 54. 
um novo quadro epistemológico. Nesta sequência se pode entender a crítica de Ricoeur a Heidegger, pela incapacidade de pensar a questão epistemológica no quadro da ontologia ${ }^{31}$. Terceira razão: se tomarmos como pressuposto que Ricoeur se movimenta no quadro de uma concepção de Filosofia entendida como discurso de unidade que se alimenta das ciências ${ }^{32}$, então trata-se fundamentalmente de encontrar um quadro conceptual satisfatório para esse fim. A hermenêutica filosófica será a concepção que permitirá integrar a «ciência» no processo interpretativo como factor mediador entre uma compreensão «ingénua» e uma compreensão «profunda» e no âmbito de uma filosofia que permanece fiel ao projecto reflexivo.

Uma última razão, talvez a mais importante, encontra-se na equivalência que Ricoeur faz entre o papel da epoche fenomenológica e o da distanciação no processo de constitução do sentido ${ }^{33}$. Isto permite-lhe integrar o momento do rigor e da objectividade no processo interpretativo (no que considera ser um mesmo «arco hermenêutico»). A atitude metodológica de "pôr à distância», praticada pelas ciências, não é senão um prolongamento do movimento geral da constituição do sentido. Seja como for, permanece a dificuldade em perceber como é que se transita do nível científico para o propriamente hermenêutico e ontológico da compreensão de si. Seguindo Paisana, poderemos colocar a questão nestes termos: como é que o «logos apofântico» nos pode conduzir ao «logos hermenêutico»? Como é que o discurso das ciências - derivado - nos pode conduzir ao nível ontológico e originário? Como é que o percurso ôntico, que segundo Heidegger é uma possibilidade de encarar o ente diferente da possibilidade ontológica, pode permitir retornar à questão ontológica? O que nos parece é que, não trabalhando suficiente e sistematicamente a distinção entre os planos ôntico e ontológico, para Ricoeur a questão da transição não chega a colocar-se, assim como, neste enquadramento, o lugar das ciências do texto não se coloca como problema.

\section{§5 O diálogo e o questionar}

A hermenêutica de Gadamer é considerada como seguidora directa do percurso anunciado por Heidegger. Segundo Gadamer, o diálogo é a estrutura do fenómeno hermenêutico, e o acto de questionar, o processo que conduz a construção da significação. O processo hermenêutico está submetido à lógica da pergunta-resposta e do que se trata é de chegar à verdade do tema em discussão. Só o questionamento

31 Segundo Ricoeur, «avec la philosophie heideggérienne, on ne cesse de pratiquer le mouvement de remontée aux fondements, mais on se rend incapable de procéder au mouvement de retour qui, de l'ontoogie fondamentale, ramènerait à la question proprement épistémologique du statut des sciences de l'esprit». Para Ricoeur, a ontologia fundamental não consegue «répéter la question épistémologique après l'ontologie» (T. A., pp. 94-95). A partir da análise que temos vindo a fazer é possível perguntar, agora a Ricoeur, e parafraseando, como repetir a questão ontológica depois da epistemologia? Não equacionando a questão da transição do nível ôntico ao ontológico, é o projecto da ontologia que se pode encontrar comprometido: encontrariamos assim uma antropologia e não uma ontologia. Esta hipótese, que os limites deste artigo não permitem trabalhar, deveria ser acompanhada da análise do conceito de «sujeito» na filosofia de Ricoeur, em articulação, nomeadamente, com os de «Dasein» e de «Soi». Afirma Ricoeur que «une philosophie que rompt le dialogue avec les sciences ne s'adresse plus qu'à elle-même». T. A., p. 94. 
permite criar a abertura que coloca o intérprete na orientação daquilo acerca do que o texto fala, assim como aferir dos preconceitos legítimos que guiam a interpretação.

Ricoeur, no entanto, confunde diálogo com oralidade que, então, não poderia dar conta do fenómeno hermenêutico. De forma repetida, aliás, Ricoeur rejeita o paradigma dialogal - que associa à hermenêutica de Schleiermacher - substituindo-o pelo paradigma da leitura. Parece esquecer que o conceito de diálógo não tem necessariamente limitado à presença dos interlocutores nem comprometido com qualquer perspectiva psicologista do compreender, como Gadamer deixa bem claro. Vemos precisamente que, segundo Gadamer, o diálogo constitui-se não só como método de pesquisa que se deixa guiar pelo tema visado, mas como correspondendo à estrutura de todo o saber ou de tudo o que é possível saber. A interpretação textual não descobre um sentido dado, descobre o sentido do texto construído a partir da situação hermenêutica do intérprete e como resposta efectiva que a interpretação coloca num campo aberto de possibilidades. A associação do diálogo à pesquisa da verdade - à dialéctica no sentido socrático - e a articulação do diálogo com a lógica da pergunta-resposta não revelam qualquer compromisso, nem com a situação de oralidade nem com qualquer perspectiva psicologista do «compreender». No entanto, estes aspectos não são considerados por Ricoeur, facto que constitui para nós uma questão. Lembramos que Gadamer é autor que Ricoeur cita frequentemente, analisando, avaliando as suas posições, revelando grande proximidade ao subscrever alguns dos seus conceitos hermenêuticos e tomando mesmo a sua obra Wahreit und Methode como «uma referência privilegiada» ${ }^{34}$.

Agora, a questão que queremos colocar diz respeito às possiveis razões do silêncio, creio que podemos chamar-lhe assim, relativamente ao diálogo nos termos em que Gadamer o coloca, assim como a pouca relevância dada à lógica da pergunta-resposta. Podemos também perguntar, se é possível fazer qualquer complemento ou «rectificação» à perspectiva gadameriana, como parece pretender Ricoeur, obliterando aquilo que, nela, deve ser considerado elemento estruturante: a lógica da pergunta-resposta, o questionar hermenêutico, o diálogo.

Na proposta de Ricoeur, é a leitura, entendida como dialéctica entre explicar e compreender e como "operação de refiguração», que substitui o diálogo. A integração do questionar como um dos momentos da leitura, coloca-o ao serviço do movimento reflexivo da tomada de consciência de/do si. Independentemente da análise que poderíamos fazer do alcance do "paradigma da leitura» na proposta da hermenêutica de Ricoeur, o que poderemos perguntar é se o esquecimento que o texto de Ricoeur patenteia, relativamente ao diálogo no sentido que anotámos e à lógica pergunta-resposta, não poderá representar a impossibilidade de os pensar conjuntamente no quadro da sua hermenêutica reflexiva?

Também aqui consideramos fecunda a intervenção de J. Paisana. Este autor opera a ruptura entre a fenomenologia explicitativa husserliana e a hermenêutica de Heidegger por via do questionar ${ }^{35}$, considerando que o carácter explicitativo e

34 Cf. Ricoeur, Réflexion faite. Autobiographie intellectuelle, Paris, Éd. Esprit, 1995; trad. portuguesa de António Moreira Teixeira, «Autobiografia Intelectual» in Paul Ricoeur, Da Metafísica à Moral, Ed. Instituto Piaget, s/d, p. 80; esta tradução foi feita a partir da publicação inglesa, "Intelectual Autobiography», trad. de Kathleen Blamey in The Philosophy of Paul Ricoeur, ed. Lewis Edwin Hahn, Chicago, Open Court, 1995.

35 «O espaço da questão, condição da própria exegese fenomenológica, tal como Heidegger a entende, encontra-se necessariamente encerrado no horizonte da fenomenologia explicitativa». Idem, F. H., p. 288. 
reflexivo da fenomenologia de Husserl encerra o sujeito na efectividade e não permite o questionamento como abertura de possibilidades. Não será possível ver, neste aspecto da hermenêutica de Ricoeur, a marca derivada da sua tese do carácter inconciliável da fenomenologia explicitativa de Husserl e da fenomenologia hermenêutica de Heidegger? O facto de a hermenêutica de Ricoeur não integrar aqueles aspectos da hermenêutica de Gadamer, é interpretado por nós como uma dificuldade interna do seu projecto e como argumento em desfavor da sua tese do carácter conciliável da fenomenologia husserliana e da fenomenologia hermenêutica de Heidegger, tal como Ricoeur sustenta, ora de modo explícito ora de modo implícito, na sua hermenêutica textual.

Foi a lucidez intelectual de J. Paisana e a precisão na exposição do seu pensamento que, ao pedir-nos uma leitura exigente, nos levou a este diálogo com a hermenêutica de Ricoeur. 